\title{
Opinion
}

\section{Dialysate Sodium-One Size Unlikely to Fit All}

\author{
Finnian R. Mc Causland
}

check for updates

Citation: Mc Causland, F.R.

Dialysate Sodium-One Size Unlikely to Fit All. Kidney Dial. 2021, 1, 135-137. https://doi.org/10.3390/ kidneydial1020016

Academic Editors: Manfred Hecking, Peter Kotanko and Jochen G. Raimann

Received: 18 November 2021 Accepted: 24 November 2021 Published: 30 November 2021

Publisher's Note: MDPI stays neutral with regard to jurisdictional claims in published maps and institutional affiliations.

Copyright: (C) 2021 by the author. Licensee MDPI, Basel, Switzerland. This article is an open access article distributed under the terms and conditions of the Creative Commons Attribution (CC BY) license (https:// creativecommons.org/licenses/by/ $4.0 /)$.
Division of Renal Medicine, Department of Medicine, Brigham and Women's Hospital, Harvard Medical School, Boston, MA 02115, USA; fmccausland@bwh.harvard.edu

\begin{abstract}
The role of medical director of a hemodialysis unit has become increasingly complex. Among the many roles it encompasses, the delivery of safe and effective dialysis treatments requires constant review, synthesis, and interpretation of the medical literature. Despite decades of experience with hemodialysis, the evidence base for dialysate prescription is relatively limited, with the choice of dialysate sodium being a prime example. The ask of this exercise was to imagine ourselves as the medical director of a new hemodialysis unit and to consider factors influencing the choice of dialysate sodium. While fiscal considerations are indeed important, one hopes that these align with the delivery of clinical care to improve patient well-being. Therefore, my approach was to focus on exploring the clinical responsibilities of a medical director in the choice of dialysate sodium. As such, after reviewing the evidence to date, my 'default' dialysate sodium prescription would be $140 \mathrm{mmol} / \mathrm{L}$, but I would retain the option of individualizing treatment for certain patients until further evidence becomes available.
\end{abstract}

Keywords: hemodialysis; dialysate sodium; outcomes

Following the 1973 extension of the Medicare program to patients with chronic kidney disease who required hemodialysis, the number of patient beneficiaries has expanded significantly and now encompasses over 480,000 patients in the US [1]. The expansion of outpatient dialysis units facilitated this growth, eventually mandating oversight from the US Centers for Medicare and Medicaid Services (CMS), which developed Conditions for Coverage $(\mathrm{CfC})$ to govern their operations. Central to the initial $\mathrm{CfC}$ was the requirement that every unit have a medical director, whose responsibilities included development and implementation of facility policies and procedures, patient education, staff training and oversight, and the delivery of safe and effective dialysis treatments [2]. Indeed, in subsequent iterations, such roles were linked to specific portions of the CfC interpretive guidelines, placing greater emphasis and responsibility on medical directors for their implementation [3].

As such, a huge responsibility comes with the position of medical director, especially with respect to the oversight of safe and effective dialysis delivery. Enter the choice of dialysate sodium concentration, which has also evolved significantly over the last few decades. As previously described, dialysate sodium was generally in the range of 127-130 mmol/L in the early days of hemodialysis, when mostly diffusive clearance predominated [4]. As technology advanced, higher efficiency treatments with more aggressive hydrostatic-drive ultrafiltration could be performed in shorter times but came with increasing frequency of adverse dialysis-associated symptoms. To counteract these, the dialysate sodium gradually increased, approaching an average of $140 \mathrm{mmol} / \mathrm{L}$, while some clinicians used even higher concentrations for select patients with intra-dialytic hypotension and dialysis-related symptoms [5]. However, use of higher dialysate sodium came with potential downsides, including thirst, inter-dialytic weight gain, and potentially higher average blood pressure $[4,6]$. With these clearly evident pros and cons, how does one select a dialysate sodium that meets the goal of delivery safe and effective therapy in contemporary medical practice? 
Typically, one would look to the literature to guide our delivery of care and to help educate the physicians, paramedical staff, and patients within our dialysis unit. Unfortunately, here, things become more complicated. The largest observational studies examining mortality and hospitalization actually report some associations of higher dialysate sodium with a lower risk of adverse outcomes, particularly among patients with lower pre-dialysis serum sodium [7-9]. In terms of clinical trials, the majority to date have been of modest size and only examined surrogate outcomes, limiting their overall interpretation and generalizability $[4-6,10]$. A recent Cochrane review ultimately came to the same conclusion, i.e., there were benefits and risks for lowering the dialysate sodium concentrations (typically $<140 \mathrm{mmol} / \mathrm{L}$ ) [11]. Despite this conundrum, the 'standard' dialysate sodium concentration has clearly decreased in US facilities in recent years [5], which, one could argue, is based largely on observational evidence and opinion [12]. This has not occurred without concerns $[5,13,14]$, but we will have to wait until large trials powered to detect differences in important clinical outcomes are reported (NCT02823821).

In the meantime, we are left to act as clinicians-trying to interpret the available evidence and to apply it to the patient in front of us. My personal approach has been to examine all aspects of each patient situation - the inter- and intra-dialytic pattern of blood pressure, inter-dialytic weight gain, session length and ultrafiltration rate, medications and timing, thirst and medications that cause dry mouth, the pre-dialysis serum sodium, cardiac status, etc. [15]. My default prescription is a dialysate sodium of $140 \mathrm{mmol} / \mathrm{L}$ - until more evidence is available, given that the mean pre-dialysis serum sodium is around $137 \mathrm{mmol} / \mathrm{L}$, I rarely use a dialysate sodium above $140 \mathrm{mmol} / \mathrm{L}$ (exceptions may be in inpatients with specific neurological issues, e.g., recent stroke). Rather, to promote hemodynamic stability, I almost always use a cooled dialysate and, on occasion, may perform isolated ultrafiltration followed by hemodialysis. Conversely, if severe hypertension or large inter-dialytic weight gains are a problem, I may consider lowering the dialysate sodium in addition to addressing the other aspects of care outlined previously. To avoid risk of recurrent hypotension, I advocate strongly for longer session length and additional ultrafiltration sessions when needed. With all of the above, it is critical to monitor the patient after institution of any change to the dialysate prescription and to adjust again as needed.

Changes to dialysate sodium from a practical perspective are cost neutral to implement. While one could argue for the simplicity of having a standard dialysate sodium across the whole unit (which may also minimize prescribing errors), having the option of tailoring to an individual patient is important, at least until more evidence becomes available. Returning to the roles of the medical director, the education of staff and patients is critical to ensure such individualization of care can be implemented safely.

Funding: This research received no external funding.

Institutional Review Board Statement: Not applicable.

Informed Consent Statement: Not applicable.

Data Availability Statement: Not applicable.

Conflicts of Interest: The author declares no conflict of interest.

\section{References}

1. USRDS. United States Renal Data System Atlas of Chronic Kidney Disease and End-Stage Renal Disease in the United States; National Institutes of Health, National Institute of Diabetes and Digestive and Kidney Diseases: Bethesda, MD, USA, 2019.

2. Maddux, F.W.; Nissenson, A.R. The Evolving Role of the Medical Director of a Dialysis Facility. Clin. J. Am. Soc. Nephrol. 2015, 10, 326-330. [CrossRef] [PubMed]

3. Department of Health and Human Services: Centers for Medicare \& Medicaid Services: 42 CFR Parts 405, 410, 413 et al. Medicare and Medicaid Programs; Conditions for Coverage for End-Stage Renal Disease Facilities. Final Rule. Fed. Regis. 2008, 73, 20369-20484.

4. Flythe, J.E.; Causland, F.R.M. Dialysate Sodium: Rationale for Evolution over Time. Semin. Dial. 2017, 30, 99-111. [CrossRef] [PubMed] 
5. Marshall, M.R.; Karaboyas, A. Temporal changes in dialysate $\left[\mathrm{Na}^{+}\right]$prescription from 1996 to 2018 and their clinical significance as judged from a meta-regression of clinical trials. Semin. Dial. 2020, 33, 372-381. [CrossRef] [PubMed]

6. Causland, F.R.M.; Waikar, S.S. Optimal Dialysate Sodium-What is the Evidence? Semin. Dial. 2014, 27, 128-134. [CrossRef] [PubMed]

7. Hecking, M.; Karaboyas, A.; Saran, R.; Sen, A.; Inaba, M.; Rayner, H.; Horl, W.H.; Pisoni, R.L.; Robinson, B.M.; Sunder-Plassmann, G.; et al. Dialysate sodium concentration and the association with interdialytic weight gain, hospitalization, and mortality. Clin. J. Am. Soc. Nephrol. CJASN 2012, 7, 92-100. [CrossRef] [PubMed]

8. Hecking, M.; Karaboyas, A.; Saran, R.; Sen, A.; Hörl, W.H.; Pisoni, R.L.; Robinson, B.M.; Sunder-Plassmann, G.; Port, F.K. Predialysis serum sodium level, dialysate sodium, and mortality in maintenance hemodialysis patients: The Dialysis Outcomes and Practice Patterns Study (DOPPS). Am. J. Kidney Dis. 2012, 59, 238-248. [CrossRef] [PubMed]

9. Causland, F.R.M.; Brunelli, S.M.; Waikar, S.S. Dialysate sodium, serum sodium and mortality in maintenance hemodialysis. Nephrol. Dial. Transpl. 2012, 27, 1613-1618. [CrossRef] [PubMed]

10. Marshall, M.R.; Vandal, A.C.; de Zoysa, J.R.; Gabriel, R.S.; Haloob, I.A.; Hood, C.J.; Irvine, J.H.; Matheson, P.J.; McGregor, D.O.R.; Rabindranath, K.S.; et al. Effect of Low-Sodium versus Conventional Sodium Dialysate on Left Ventricular Mass in Home and Self-Care Satellite Facility Hemodialysis Patients: A Randomized Clinical Trial. J. Am. Soc. Nephrol. 2020, 31, $1078-1091$. [CrossRef] [PubMed]

11. Dunlop, J.L.; Vandal, A.C.; Marshall, M.R. Low dialysate sodium levels for chronic haemodialysis. Cochrane Database Syst. Rev. 2019, 1, CD011204. [CrossRef] [PubMed]

12. Weiner, D.E.; Brunelli, S.M.; Hunt, A.; Schiller, B.; Glassock, R.; Maddux, F.W.; Johnson, D.; Parker, T.; Nissenson, A. Improving clinical outcomes among hemodialysis patients: A proposal for a "volume first" approach from the chief medical officers of US dialysis providers. Am. J. Kidney Dis. 2014, 64, 685-695. [CrossRef] [PubMed]

13. Port, F.; Hecking, M.; Karaboyas, A.; Pisoni, R.; Robinson, B. Current evidence argues against lowering the dialysate sodium. Nephrol News Issues 2013, 27, 18-21. [PubMed]

14. Hecking, M.; Rayner, H.; Port, F.K. More evidence needed before lower dialysate sodium concentrations can be recommended. Am. J. Kidney Dis. 2015, 65, 519-520. [CrossRef] [PubMed]

15. Reeves, P.B.; Causland, F.R.M. Mechanisms, Clinical Implications, and Treatment of Intradialytic Hypotension. Clin. J. Am. Soc. Nephrol. 2018, 13, 1297-1303. [CrossRef] [PubMed] 